\title{
Social facilitation of pecking following differential rearing
}

\author{
CATHRYN P. BROWN \\ Behavioural Sciences, Macquarie University, North Ryde, N.S.W. 2113, Australia
}

\begin{abstract}
White-Leghorn $\times$ Black-Orpington chicks were reared socially, in isolation, or were isolated and exposed to an artificial stimulus at $16 \mathrm{~h}$. They were tested at 24,48 , or $72 \mathrm{~h}$ for pecking in the presence of another chick, of the artificial stimulus, or in isolation. Socially reared chicks pecked more during pair-testing than in isolation, and showed no increase in pecking with the artificial stimulus. Imprinted chicks pecked most with the artificial stimulus, but showed a slight increase in pecking during pair-testing compared with isolation. Isolates showed similarly low peck rates under all conditions. These results, showing the importance of familiarity with test conditions in facilitation, were interpreted as consistent with an arousal-reduction account of facilitation. The importance of stimulus movement was also discussed, both as a potential dimension of stimulus generalization and as a factor in maintaining a minimum level of arousal essential to responding.
\end{abstract}

Arousal has been differently implicated in social facilitation by Zajonc $(1965,1968)$ and Bovard (1959), who have proposed, respectively, that the social companion increases general arousal so activating all behavior, and that the companion reduces high levels of arousal induced by the test situation, blocking fear-dependent inhibition of ongoing activity, thereby "disinhibiting" the relevant response. These two views, however, need not be mutually incompatible as accounts of pecking facilitation in chicks. Each may apply to a different range of test conditions. Zajonc's proposal may account for increased responding with a companion when the isolation test situation elicits low arousal, or even drowsiness and consequent low responding in the test chick. Under such conditions, the companion may serve to awaken or alert the test chick. On the other hand, chicks tested under conditions normally eliciting high arousal or fear may show behavioral inhibition, which is reduced, in accordance with Bovard's account, by a companion, resulting in increased ongoing behavior, such as pecking.

Consistent with the arousal-reduction argument are reports of (1) negative correlations between peck rates and accepted indices of arousal (Tolman, 1965); (2) facilitated pecking following independently reduced general arousal (Brown \& Kiely, 1974); (3) greater social facilitation when social test conditions are familiar (Brown \& Kiely, 1974; Hogan \& Abel, 1971; May \& Dorr, 1968; Strobel, Freedman, \& Macdonald, 1970), presumably eliciting lower

This paper was originally received during the tenure of the previous editor, Abram Amsel. This research was assisted by a Macquarie University research grant. arousal in the test chick (Moltz, 1968; Rajecki, 1972; Strobel \& Macdonald, 1974; Zajonc, Markus, \& Wilson, 1974; Zajonc, Reimer, \& Hausser, 1973); and (4) the effectiveness in increasing pecking of artificial stimuli which have previously acquired the capacity to elicit approach from the chick (Strobel \& Macdonald, 1974), this stimulus now serving to reduce arousal (Bateson, 1966; Sluckin, 1972).

Yet, facilitation is also observed in chicks previously exposed to an artificial stimulus and tested with other chicks (Strobel, Freedman, \& Macdonald, 1970). This can be accommodated within an arousalreduction account only by assuming some stimulus generalization between the stimulus and companion chicks, and thus some degree of arousal reduction in the presence of the latter (Strobel \& Macdonald, 1974). If this is the case, then, although some facilitation might be apparent with other chicks, the familiar stimulus itself should elicit even more responding, since arousal should be more significantly reduced by its presentation.

A second potential restriction on the usefulness of an arousal-reduction account comes from the apparent need for rhythmic movement of even familiar artificial stimuli in the test situation if pecking is to be facilitated (Strobel \& Macdonald, 1974). However, in this study, test sessions were of 30 to 45 min duration. It may have been that arousal levels gradually became so low during this time that some degree of movement or stimulation was necessary to awaken the test chick and increase arousal to a level necessary for any behavior. Such possibility would accord with the arousal-increment proposal of Zajonc $(1965,1968)$. Stationary familiar stimuli may be effective in facilitating pecking over a shorter 
test period where chicks are unlikely to fall asleep.

In this study, the relative effectiveness of an artificial stimulus and a companion chick in pecking facilitation was assessed after social rearing, and previous "imprinting" exposure to the artificial stimulus. A short test session was used to reduce the possibility of drowsiness developing in test chicks, and chicks showing very low arousal, or sleepiness, before testing were not tested further. If arousal reduction were critical, it was argued that pecking facilitation would be greater in the presence of a familiar stimulus, whether artificial or another chick. Moreover, by ensuring relative alertness in the test chick, facilitation should be apparent even with a stationary familiar stimulus, compared with peck rates observed under control or isolation test conditions. To further determine the impact of rearing and stimulus familiarity, pecking in the presence of both stimuli was assessed in totally isolated chicks for whom both stimuli, artificial and another chick, would be unfamiliar.

\section{METHOD}

\section{Subjects}

Two hundred and seventy White-Leghorn $\times$ Black-Orpington eggs were obtained from a local hatchery and incubated and hatched in the laboratory. At hatching, all chicks were marked indelibly and the hatch time was recorded. They were assigned, in order of hatching, to a social rearing condition, to a group to be reared in isolation, or to a group to be isolated but also "imprinted" to an artificial stimulus. Socially reared chicks were housed 30 per group in large aluminum tubs maintained at $28^{\circ} \mathrm{C}$. Isolated and imprinted groups were placed, at hatching, in individual compartments of an aluminum tub, $1 \mathrm{~m}$ in diameter and divided into 20 segments, and also maintained at $28^{\circ} \mathrm{C}$ by an overhead brooder light. In the three groups, the floor was spread with sawdust. Food was placed in fixed dishes in each compartment of the isolation tub, and water was available from externally placed dispensers. Food was removed from all chicks $6 \mathrm{~h}$ prior to testing for pecking.

Chicks in the imprinted group were exposed to the stimulus in a small enclosed chamber. The floor, measuring $2 \times 2 \mathrm{~m}$, was marked into 36 equal, numbered squares. A camera fitted to the ceiling of the chamber transmitted to a closed-circuit television receiver located in an adjacent room. The imprinting stimulus was a red cardboard cylinder placed over a small platform, the wheels of which were driven by a small motor. The cylinder was $15 \mathrm{~cm}$ in diameter and $20 \mathrm{~cm}$ in height. The movement of the base platform was under remote control, and the cylinder could thereby be maneuvered right, left, or forward. Speed of movement was fixed at approximately $1 \mathrm{~m} / 12 \mathrm{sec}$, but, by alternately turning the motor on and off, the actual movement of the stimulus could be retarded if necessary. It should be noted that, while the stimulus moved during exposure, this movement was not of that internal rhythmic type used by Strobel and Macdonald (1974). Nor was this stimulus moved during subsequent facilitation testing, the stage at which movement appears to be most important (Strobel \& Macdonald, 1974). The temperature of the test chamber was maintained at approximately $40^{\circ} \mathrm{C}$.

The social facilitation test box was of white perspex, $25 \times$ $35 \mathrm{~cm}$ and $15 \mathrm{~cm}$ in height. The lid was of wire mesh, above which was suspended a 100-W heater globe providing light and warmth. The floor was scattered with grain. The stimulus chick or the imprinting stimulus were placed in the center of the test box at the start of the appropriate test sessions. The imprinting stimulus was not moved about within the test box as had been the case during imprinting.

\section{Procedure}

The imprinted chicks were exposed to the stimulus at $16 \mathrm{~h}$ posthatch. Imprinting was begun by placing the chick by hand, with its head covered, directly from the housing box into the center of the marked floor, in the same square as the stimulus. The training-test session lasted a maximum of $30 \mathrm{~min}$ and involved movement of the stimulus in a circling pattern out of that square and back again every $2 \mathrm{~min}$. The stimulus was left in an adjacent square for $1 \mathrm{~min}$ on each excursion. The latency for an approach to the stimulus in the adjacent square on the part of the test bird was recorded. This procedure was repeated until the bird made three such "approaches" over five excursions, or until testing had continued for $30 \mathrm{~min}$. If chicks "approached" before $30 \mathrm{sec}$, they were left with the stimulus, which no longer moved, for the rest of the 30-min session. Only those birds reaching this "approach criterion" within the test session were subsequently tested for social facilitation of pecking.

All chicks were tested for pecking under one of three stimulus conditions, with the artificial stimulus, another chick (Pair testing), or no other stimulus present (control). During testing, pecks at both the ground and the walls were scored. Pecks at the stimulus or the other chicks were discounted. The results of $\mathbf{3 0}$ chicks from each rearing condition tested at 24,48 , or $72 \mathrm{~h}$, with 10 birds tested under each stimulus condition, were used. Before each test session, the chicks were given 10 min adaptation to the test box with the relevant stimulus absent. If the test bird pecked during or at the end of that time, the appropriate stimulus was presented and the number of pecks given in the next 2 min was recorded, using a hand counter. During the last minute of the adaptation period, attempts were made to elicit pecking if the chick had not pecked, using a tapping red pencil (Tolman, 1967a, 1967b). If the chick failed to peck, it was not tested further. It was found that nonpecking chicks generally failed to peck because they became drowsy in the test box. Thus, this procedure ensured that all chicks were sufficiently aroused to show some pecking even under conditions of no stimulation. Sixteen socially reared, 12 imprinted, and 17 total isolates were so discarded.

In any given week of testing, 10 separately housed socially reared birds, of similar age to the tested chicks, were used as stimulus birds during pair testing. Stimulus chicks were deprived of food $12 \mathrm{~h}$ prior to use as social companions. During this time, these chicks were also housed in pairs, in boxes similar to the test box, in order to reduce unfamiliarity with the test situation itself and any resultant heightened fear which may have reduced their peck rate. No chick was used as a stimulus for more than $12 \mathrm{~min}$, in order to ensure a uniformly high peck rate from all stimulus chicks.

\section{RESULTS AND DISCUSSION}

Table 1 gives the group means and standard deviations of the number of pecks during the 2-min test period. The data were treated in a three-way analysis of variance. Significant effects on pecking were observed due to rearing, $F(2,243)=7.48, p<.001$, the test stimulus, $\mathrm{F}(2,243)=11.94, \mathrm{p}<.001$, and their interaction, $F(4,243)=19.26, p<.001$. No change in pecking was observed over the ages tested. In view of this, the results for the three rearing and three test conditions were averaged over the three test ages and post hoc comparisons were used to determine in more detail the nature of the treatment effects (Scheffé, 1959). The resulting peck rates are given in Figure 1, together with a statement of those relevant individual group comparisons reaching significance. These results generally indicate that the main effects of rearing and of testing were due to 
Table 1

Number of Pecks During Testing: Means and Standard Deviations

\begin{tabular}{|c|c|c|c|c|c|c|c|}
\hline \multirow{3}{*}{$\begin{array}{c}\text { Rearing } \\
\text { Treatment }\end{array}$} & \multirow{3}{*}{$\begin{array}{l}\text { Test Age } \\
\text { (Hours) }\end{array}$} & \multicolumn{6}{|c|}{ Test Conditions } \\
\hline & & \multicolumn{2}{|c|}{ Pair Testing } & \multicolumn{2}{|c|}{ Artificial Stimulus } & \multicolumn{2}{|c|}{ Control } \\
\hline & & Mean & SD & Mean & SD & Mean & SD \\
\hline Social & $\begin{array}{l}24 \\
48 \\
72\end{array}$ & $\begin{array}{l}38.2 \\
29.7 \\
36.3\end{array}$ & $\begin{array}{l}10.81 \\
11.48 \\
10.67\end{array}$ & $\begin{array}{l}14.9 \\
13.9 \\
15.1\end{array}$ & $\begin{array}{l}9.02 \\
7.42 \\
9.71\end{array}$ & $\begin{array}{l}14.1 \\
15.1 \\
18.8\end{array}$ & $\begin{array}{l}7.68 \\
7.48 \\
7.4\end{array}$ \\
\hline Isolated & $\begin{array}{l}24 \\
48 \\
72\end{array}$ & $\begin{array}{l}12.3 \\
16.3 \\
19.0\end{array}$ & $\begin{array}{c}7.96 \\
11.1 \\
8.8\end{array}$ & $\begin{array}{l}14.6 \\
17.3 \\
15.5\end{array}$ & $\begin{array}{l}9.31 \\
8.72 \\
8.98\end{array}$ & $\begin{array}{l}14.0 \\
19.5 \\
18.2\end{array}$ & $\begin{array}{c}10.7 \\
8.91 \\
9.04\end{array}$ \\
\hline Imprinted & $\begin{array}{l}24 \\
48 \\
72\end{array}$ & $\begin{array}{l}14.2 \\
18.5 \\
22.1\end{array}$ & $\begin{array}{l}9.25 \\
6.89 \\
6.91\end{array}$ & $\begin{array}{l}27.2 \\
21.8 \\
26.2\end{array}$ & $\begin{array}{r}9.17 \\
10.48 \\
10.84\end{array}$ & $\begin{array}{l}13.1 \\
14.2 \\
17.9\end{array}$ & $\begin{array}{l}8.01 \\
8.31 \\
9.37\end{array}$ \\
\hline
\end{tabular}

greatly increased pecking by socially reared chicks in pair-test conditions, and a smaller increase by imprinted chicks with the artificial stimulus. Isolation rearing and testing produced the lowest overall peck rates of any rearing or testing conditions.

In terms of the main questions considered here, the increased pecking by imprinted chicks in the presence of the artificial stimulus compared with isolation testing $(p<.05)$ confirms that familiarity with the stimulus can be effective in facilitating responding even when that stimulus is stationary. Consistent with this inference, imprinted chicks showed higher pecking with the stimulus than did either isolated $(\mathrm{p}<.05)$ or socially reared birds $(\mathrm{p}<.01)$.

It was also found that the increase in pecking by imprinted chicks with the artificial stimulus was not significantly different from the peck rates observed under pair-test conditions, which were midway between those of stimulus-test and isolation-test conditions. This slight elevation in pecking with pair-testing compared with isolation testing was not observed

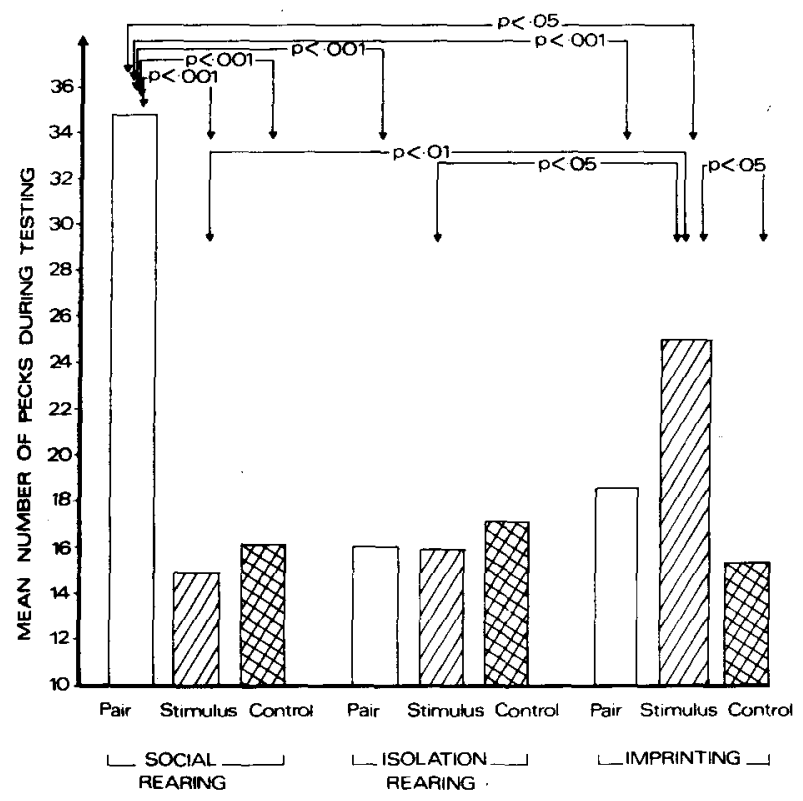

Figure 1. following isolation rearing, suggesting that exposure to the artificial stimulus did have some effect towards facilitation with pair-testing. Such a result is consistent with the earlier results of Strobel, Freedman, and Macdonald (1970). If, as Strobel and Macdonald (1974) suggest, this facilitation is due to some form of stimulus generalization from the artificial stimulus to the chick and thus arousal-reduction by the latter, the question remains as to what stimulus dimension is common to both a chick and the artificial stimulus of this study. The property of movement itself may constitute a generalization stimulus characteristic, the artificial stimulus showing regular movement during the imprinting exposure itself, though not in testing.

Further, consistent with the suggested importance of familiarity and arousal reduction is the observation of higher peck rates with pair-testing shown by socially reared compared with either isolated $(p<.001)$ or imprinted chicks $(p<.05)$. Such a result confirms a previously reported interaction between rearing and testing conditions (Brown \& Kiely, 1974; May \& Dorr, 1968; Strobel, Freedman, \& Macdonald, 1970; Strobel \& Macdonald, 1974). Additionally, the fact that isolates showed no increase in pecking in either pair- or stimulus-test conditions indicates that these stimuli themselves, unless familiar, were ineffective in facilitating pecking.

Nevertheless, the higher peck rates shown by socially reared and tested birds compared with imprinted and stimulus tested birds $(\mathrm{p}<.05)$ suggests certain limits to the effectiveness of familiarity with the test conditions, determined by the properties of the stimulus itself, although the stimulus conditions must be themselves familiar for such properties to be important (Strobel \& Macdonald, 1974). Responsiveness in the presence of a familiar and mobile stimulus would appear greater than that with a familiar stationary stimulus, although the possibility that, in the present study, continued proximity to other chicks a stronger association than the imprinting exposure cannot be discounted. This would be consistent with reports of the gradual nature of the 
imprinting process (Zajonc, Markus, \& Wilson, 1974; Zajonc, Reimer, \& Hausser, 1973).

In general, these results confirm the role of arousal-reduction through familiarity with the stimulus testing conditions in pecking facilitation. The importance of the basic arousal level under control testing conditions is, however, emphasized. Other properties of the stimulus, particularly movement, become critical if level of arousal is relatively low. Clearly, independent assessment of arousal is nevertheless essential for confirmation of this interpretation, "peep" vocalization (Collias \& Joos, 1953) and mobility providing the generally accepted indices of arousal. However, inconsistencies in the relationship observed between these responses and arousal, manipulated independently, make this difficult at the present stage. Vocalization and mobility increase as arousal decreases in situations where initial arousal may have been excessive due to the nature of the test procedure (Candland, Nagy, \& Conklyn, 1963; Ginsburg, Braud, \& Taylor, 1974), but decrease with reduced arousal, produced by familiar stimuli or a return to the conditions of rearing (Rajecki, 1972; Zajonc, Reimer \& Hausser, 1973; Zajonc, Markus \& Wilson, 1974), when possibly the initial level of arousal produced by testing may not have been excessive. Thus vocalization, in particular, may represent an inverted-U-shaped function of arousal. Again, vocalization and mobility decrease with increased arousal produced by an auditory startle stimulus (Kruijt, 1964) but increase upon presentation of a visual stimulus (Phillips \& Siegel, 1966; Schaller \& Emlen, 1962). Test age may also be important in the relationship between arousal and these indices. The capacity to inhibit vocalization and movement in fear-producing situations where silence may be of greater survival value appears to emerge gradually over the first few days posthatch (Fischer, 1976). Thus, an accurate assessment of arousal, and its relationship to facilitation, requires further analysis of the elements of the "facilitating" stimulus critical to responding, of the basic level of arousal likely to be induced by the various experimental procedures, and closer consideration of test age before these responses can provide reliable and necessary independent indices of arousal.

\section{REFERENCES}

Bateson, P. P. G. The characteristics and context of imprinting. Biological Review, 1966, 41, 177-220.

Bovard, E. W. The effects of social stimuli on the response to stress. Psychological Review, 1959, 66, 267-277.

Brown, C. P., \& KIELY, P. C. The role of early experience and emotionality in social facilitation of pecking in chickens. Animal Behaviour, 1974, 22, 100-109.
Candland, D. K., Nagy, Z. M., \& Conklyn, D. H. Emotional behavior in the domestic chicken (White Leghorn) as a function of age and developmental environment. Joumal of Comparative and Physiological Psychology, 1963, 56, 1069-1073.

Collras, N. E., \& Joos, M. The spectrographic analysis of sound signals of the domestic fowl. Behaviour, 1953, 55, 175-188.

Fischer, G. J. The behavior of chickens. In E. S. E. Hafez (Ed.), The behavior of domestic animals. London: Bailliere, Tindall \& Cassell, 1976.

GinsBurg, H. J., Braud, W. G., \& TAYLoR, R. D. Inhibition of distress vocalisation in the open field as a function of heightened fear or arousal in the domestic fowl (Gallus gallus). Animal Behaviour, 1974, 22, 745-759.

HogAN, J. A., \& ABEL, E. L. Effects of social factors on response to unfamiliar environments in Gallus gallus spadicaus. Animal Behaviour, 1971, 19, 687-694.

KRUIJT, J. P. Ontogeny of social behaviour in Burmese Red Junglefowl (Gallus gallus spadiceus). Behaviour, 1964, Suppl 12.

MAY, J. G, \& DORR, D. Imitative pecking in chicks as a function of early social experience. Psychonomic Science, 1968, 11. 175-176.

MoLTz, H. An epigenetic interpretation of the imprinting phenomenon. In G. Newton \& S. Levine (Eds.), Early experience and behavior. Springfield: Thomas, 1968.

Phillips, R. E., \& Siegel, P. B. Development of fear in chicks of two closely related genetic lines. Animal Behaviour, 1966, 14, 84-88.

RAJECKI, D. W. Effects of prenatal exposure to auditory and visual stimuli on social responses in chicks. Unpublished doctoral dissertation, University of Michigan, 1972.

SChaller, G. B., \& EMLEN, J. T. The ontogeny of avoidance behaviour in some precocial birds. Animal Behaviour, 1962, 10, 370-381.

SCHEFFE, H. The analysis of variance. New York: Wiley, 1959.

SLuCXIN, W. Imprinting and early leaming. London: Methuen, 1972.

Strobel, M. G., Freedman, S. L., \& Macdonald, G. E. Social facilitation of feeding in newly hatched chickens as a function of imprinting. Canadian Joumal of Psychology, 1970, 24, 207-215.

Strobel, M. G., \& Macdonald, G. E. Induction of eating in newly hatched chicks. Journal of Comparative and Physiological Psychology, 1974, 86, 493-502.

Tolman, C. W. Emotional behaviour and social facilitation of feeding in domestic chicks. Animal Behaviour, 1965, 13, 493-496.

Tolman, C. W. The effects of tapping sounds on feeding behaviour of domestic chicks. Animal Behaviour, 1967, 15, 145-148. (a)

Tolman, C. W. The feeding behaviour of domestic chicks as a function of rate of pecking by a surrogate companion. Behaviour, $1967,29,57-62$. (b)

ZAJONC, R. B. Social facilitation. Science, 1965, 149, 269-274.

ZAJONC, R. B. Social facilitation in cockroaches. In E. C. Simmel, R. H. Hoppe, \& G. A. Milton (Eds.), Social facilitation and imitative behavior. Boston: Allyn \& Bacon, 1968.

Zajonc, R. B., Markus, H., \& Wilson, W. R. Exposure, object preference, and distress in the domestic chick. Journal of Comparative and Physiological Psychology, 1974, 86, 581-585.

ZAJONC, R. B., REIMER, D. J., \& HAUSSER, D. Imprinting and the development of object preference in chicks by mere repeated exposure. Journal of Comparative and Physiological Psychology, $1973,83,434-440$.

(Received for publication June 1976; revision accepted May 1977.) 